\title{
Signaling from plant endosomes: compartments with something to say!
}

\author{
Natasha Raikhel ${ }^{1}$ and Glenn Hicks \\ Institute for Integrative Genome Biology and Center for Plant Cell Biology, University of California at Riverside, \\ Riverside, California 92521, USA
}

It is well established in animal systems that compartmentalization of signaling receptors within the endocytic pathway contributes to signaling specificity and regulation (Miaczynska et al. 2004; Fischer et al. 2006). Multiple examples have been reported in vertebrates that demonstrate this concept. Epidermal growth factor receptor (EGFR) is found at the plasma membrane, but when clathrin-mediated endocytosis is impaired, downstream signaling components such as mitogen-activated protein kinases (MAPKs) have reduced activity (Viera et al. 1996). In endosomes, EGFR has been shown to interact with other signaling components (Sorkin et al. 2000). In fact, treatment with a chemical that causes the internalization of inactive (dephosphorylated) ligand-bound receptors, followed by chemical washout, reveals that the endosomal pool of EGFRs is able to promote signaling and a biological response (Pennock and Wang 2003). As important, the plasma membrane and endosomal pools of EGFR appear to be functionally distinct in that the pools show selectivity in their association with other signaling components (Burke et al. 2001). Other examples of active receptor association with endosomes include nerve growth factor association with its receptor TrkA and phospholipase C (Grimes et al. 1996) and the G-protein-coupled $\beta_{2}$-adrenergic receptor (Daaka et al. 1998). The TGF- $\beta$ receptor forms heteromeric complexes that undergo endocytosis and phosphorylation. This endosomal complex in turn phosphorylates and activates the transcription factor R-Smad2, which is targeted to the nucleus. A central modulator of endosomal signaling appears to be SARA (Smad anchor for receptor activation) (Tsukazaki et al. 1998), which serves as an adaptor between the TGF- $\beta$ complex and R-Smad2 (Fig. 1). Endocytosis and endosomal signaling pathways have also been characterized in Drosophila, where they are critical for development via the establishment of morphogen gradients and signaling involving endosomal complexes. In Drosphila, the TGF- $\beta$-like morphogen Decapentaplegic (Dpp) is involved in wing disc formation via gradients originating from secretory cells. Endocytosis, as well as

\footnotetext{
${ }^{1}$ Corresponding author.
}

E-MAIL Natasha.raikhel@ucr.edu; FAX (951) 827-2155.

Article is online at http://www.genesdev.org/cgi/doi/10.1101/gad.1577607. control of extracellular diffusion (via heparin sulfate proteoglycans), contribute to establishment of the intracellular and extracellular components of the gradient, respectively. As with TGF- $\beta$ in vertebrates, a SARA-like homolog has been identified (Bennett and Alphey 2002) and several lines of evidence suggest that Dpp may be involved in signaling that is dependent upon endocytosis and endosomes in a TGF- $\beta$-analogous manner (Bennett and Alphey 2002; for review, see Fischer et al. 2006).

Although there are as many, if not more, endomembrane trafficking components known in plants, the specific involvement of the endocytic pathway in plant receptor signaling has not been well documented. Potential receptors have also been identified. The largest class of plasma membrane receptors (most of which are orphan) appears to be the receptor-like kinases (RLKs), of which there are $>600$ in Arabidopsis and at least 1100 in rice (Morillo and Tax 2006). In spite of this, little is known about trafficking of RLKs, and recent examples in plants have largely pointed toward endocytosis as supporting either the recycling of transporters or as a route for protein turnover.

The small molecule plant hormone, auxin, is essential for many aspects of plant development and response to environmental cues such as light and the directional growth of roots and stems in response to gravity. The movement of auxin is controlled by a family of plasma membrane efflux transporters known as PIN (PINFORMED), whose major role is to establish concentration gradients of auxin across organs that ultimately respond to the hormone via asymmetric growth (Tanaka et al. 2006; Teale et al. 2006; Kerr and Bennett 2007; Zazimalova et al. 2007). For example, differences in lateral growth rates across organs result in the familiar downward bending of roots toward gravity. In roots, the PIN1 transporter is recycled between endosomes and the plasma membrane, and this mechanism along with protein turnover in the vacuole, is thought to be important for establishing and controlling auxin gradients. Moreover, auxin can block endocytosis of PIN1 providing a feedback mechanism, whereby the morphogen itself can influence transporter abundance at the plasma membrane, and thus, efflux and gradient orientation (Paciorek et al. 2005). Interestingly, it is not known in this case 


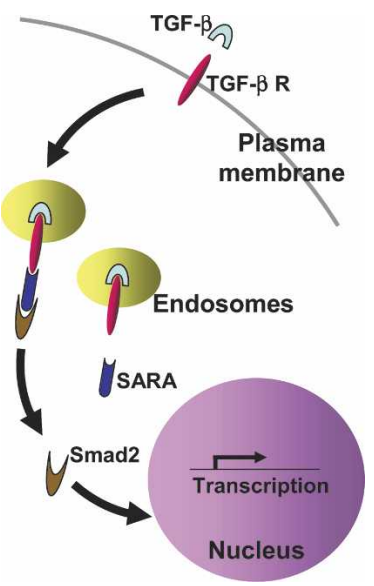

Figure 1. A greatly simplified overview showing the general concept of endosome-mediated signaling. As an example, several elements of TGF- $\beta$ signaling via the endosomal compartment are highlighted. Following ligand (TGF- $\beta$; light blue) interaction with a plasma membrane-localized receptor (TGF- $\beta$ R; magenta), the ligand-receptor complex is endocytosed and sequestered during transit in a specific endosome population. In the case of TFG- $\beta$ R, a heteromeric complex is internalized, but is not shown for simplicity. In the endosome (yellow), the cytoplasmic domain of the activated receptor interacts with an adaptor protein (the FYVE protein SARA; dark blue) that mediates interaction with a transcription factor (Smad2; brown). In this example, Smad2 is phosphorylated, leading to its translocation to the nucleus (purple) and activity in transcriptional activation. This general concept is now being discovered in plant systems, indicating that endosomal signaling is an evolutionarily conserved biological mechanism.

what the actual target of auxin is in influencing endocytosis or whether that target is localized to endosomes. In another example of endocytosis, the borate transporter, BOR1, localizes preferentially at the plasma membrane in roots under borate starvation. However, upon reintroduction of borate to the growth medium, BOR1 quickly undergoes endocytosis and targeting to the vacuole for degradation (Takano et al. 2005). As with the auxin transporters, there is no evidence of signaling from endosomes as might be expected in these examples that involve transporters that are recycled. But what about examples of plasma membrane receptors? Fortunately, new ground has been broken.

Brassinosteroids (BRs) are plant polyhydroxylated steroid hormones that are essential for plant growth, differentiation, and development (Vert et al. 2005). Unlike animal steroid hormones, BRs are sensed by a plasma membrane-localized receptor. The RLK BRIl is known to traffic through endosomes and belongs to a subclass of RLKs known to contain leucine-rich repeats (LRRs). BR interaction with BRIl also results in heterodimerization (Russinova et al. 2004) and signaling events leading to the dephosphorylation of the transcription factor BES1 and reduced expression of the BR response genes. Mutants in the BRI1 gene are extremely dwarfed and completely BR-insensitive.

In this issue of Genes \& Development, Geldner et al.
(2007) demonstrate that the BRI1 receptor of Arabidopsis thaliana is present in several locations. BRIl is known to be at the plasma membrane; however, colocalization of BRI1-GFP with the endocytic dye FM4-64 and the TGN/ endosome marker VHA1-RFP (Dettmer et al. 2006) indicates that BRIl is at least partially localized in endosomes (Russinova et al. 2004). The amount of BRI1 in the endosome pool does not increase following treatment of roots with the ligand brassinolide (BL) or even depletion of endogenous $\mathrm{BL}$, indicating that recycling itself is constitutive and not affected by ligand. When the endosomal pool is increased by the application of brefeldin A (BFA), a widely used inhibitor of endosomal trafficking, the result is dephosphorylation of BR-regulated transfer factor BES1 and reduced expression of the early BR-response gene DWF4. Pulse-chase indicates that BRI-GFP is eventually targeted to the vacuole, and BFA blocks this trafficking. The dephosphorylation of endosomal BES1 in cultured roots also occurs with $\mathrm{BL}$, and there appears to be an additive effect when seedlings are treated with both compounds. The results cannot be attributed to changes in BRI1 protein turnover, because half-life experiments indicated no differences in BL-treated and BLuntreated plants. Thus, Geldner et al. (2007) argue that the endosomal pool of BRIl is functional. This is bolstered by the finding that a YFP fusion of the known BRI1-interacting inhibitory protein BKIl colocalizes with BRI1-GFP at the plasma membrane and not in endosomes, suggesting that endosomal BRIl is active in signaling.

The overall results point toward two functionally distinct pools of BRI1: plasma membrane and endosome. Geldner et al. (2007) propose a model in which BRI1 at the plasma membrane may function in binding of a BR ligand. However, it is the endosomal pool that is functional in signal transduction, leading to BES1 activation and transcriptional regulation of DWF4. Geldner et al. (2007) put forth the exciting possibility that an as-yetunidentified downstream target is stored in the endosome, then activated directly by an endosomal receptor complex. Such a complex could have analogies to models of TGF- $\beta$ receptor signaling in animals. This report is highly significant in being one of the first examples in plants of ligand-independent trafficking in which a receptor is likely to be active in endosomes after binding ligand at the plasma membrane.

Plants have evolved various approaches to receptor action. Recently, ligand-dependent trafficking of the plant LRR RLK FLS2 was demonstrated (Robatzek et al. 2006). Thus, in plants, as in animals, two types of receptor trafficking have evolved: ligand dependent and ligand independent. One of the great challenges in plant cell biology today is to characterize the numerous endosomal compartments that exist and identify their cargoes and sorting mechanisms. Undoubtedly, when this is accomplished, many facets of plant growth and development will become apparent. Not all decisions are made at the plasma membrane and nucleus! The article by Geldner et al. (2007) is a significant step in providing a framework to begin to unravel the mystery of plant endosomes. 


\section{References}

Bennett, D. and Alphey, L. 2002. PP1 binds SARA and negatively regulates DPP signaling in Drosophila melanogaster. Nat. Genet. 31: 419-423.

Burke, P., Schooler, K., and Wiley, H.S. 2001. Regulation of epidermal growth factor receptor signaling by endocytosis and intracellular trafficking. Mol. Biol. Cell 12: 1897-1910.

Daaka, Y., Luttrell, L.M., Ahn, S., Della Rocca, G.J., Ferguson, S.S., Caron, M.G., and Lefkowitz, R.J. 1998. Essential role for G-protein-coupled receptor endosytosis in the activation of mitogen-activated protein kinase. J. Biol. Chem. 273: 685688.

Dettmer, J., Hong- Hermesdorf, A., Stierhof, Y.D., and Schumacher, K. 2006. Vacuolar H+ATPase activity is required for endocytic and secretory trafficking in Arabidopsis. Plant Cell 18: 715-730.

Fischer, J., Eun, S.H., and Doolan, T.B. 2006. Endocytosis, endosome trafficking, and the regulation of Drosophila development. Annu. Rev. Cell Dev. Biol. 22: 181-206.

Geldner, N., Hyman, D.L., Wang, X., Schumacher, K., and Chory, J. 2007. Endosomal signaling of plant steroid receptor kinase BRI1. Genes \& Dev. (this issue), doi: 10.1101/ gad.1561307.

Grimes, M.L., Zhou, J., Beattie, E.C., Yuen, E.C., Hall, D.E., Valletta, J.S., Topp, K.S., LaVail, J.H., Bunnett, N.W., and Mobley, W.C. 1996. Endocytosis of activated TrkA: Evidence that nerve growth factor induces formation of signaling endosomes. J. Neurosci. 16: 7950-7964.

Kerr, I.D. and Bennett, M.J. 2007. New insights into the biochemical mechanisms regulating auxin transport in plants. Biochem. J. 401: 613-622.

Miaczynska, M., Pelkmans, L., and Zerial, M. 2004. Not just a sink: Endosomes in control of signal transduction. Curr. Opin. Cell Biol. 16: 400-406.

Morillo, S.A. and Tax, F.E. 2006. Functional analysis of receptor-like kinases in monocots and dicots. Curr. Opin. Plant Biol. 9: 460-469.

Paciorek, T., Zazimalova, E., Ruthardt, N., Petrasek, J., Stierhoff, Y.D., Kleine-Vehn, J., Morris, D.A., Emans, N., Jurgens, G., Geldner, N., et al. 2005. Auxin inhibits endocytosis and promotes its own efflux from cells. Nature 435: 1251-1256.

Pennock, S. and Wang, Z. 2003. Stimulation of cell proliferation by endosomal epidermal growth factor receptors revealed through two distinct phases of signaling. Mol. Cell. Biol. 23: 5803-5815.

Robatzek, S., Chichilla, D., and Boller, T. 2006. Ligand-induced endocytosis of the pattern recognition receptor FLS2 in Arabidopsis. Genes \& Dev. 20: 537-542.

Russinova, E., Borst, J.-W., Kwaaitaal, M., Cano-Delgado, A., Yin, Y., Chory, J., and de Vries, S.C. 2004. Heterodimerization and endocytosis of Arabidopsis brassinosteroid receptors BRI1 and AtSERK3 (BAK1). Plant Cell 16: 3216-3229.

Sorkin, A., McClure, M., Huang, F., and Carter, R. 2000. Interaction of EGF receptor and grb2 in living cells visualized by fluorescence resonance energy transfer (FRET) microscopy. Curr. Biol. 10: 1395-1398.

Takano, J., Miwa, K., Yuan, L., von Wiren, N., and Fujiwara, T. 2005. Endocytosis and degradation of BOR1, a boron transporter of Arabidopsis thaliana, regulated by boron availability. Proc. Nat1. Acad. Sci. 102: 12276-12281.

Tanaka, H., Dhonukshe, P., Brewer, P.B., and Frimal, J. 2006. Spatiotemporal asymmetric auxin distribution: A means to coordinate plant development. Cell. Mol. Life Sci. 63: 27382754.

Teale, W.D., Paponov, I.A., and Palme, K. 2006. Auxin in action:
Signalling, transport and the control of plant growth and development. Nat. Rev. Mol. Cell Biol. 7: 847-859.

Tsukazaki, T., Chiang, T.A., Davidson, A.F., Attisano, A.F., and Wrana, J.L. 1998. SARA, a FYVE domain protein that recruits Smad2 to the TGF $\beta$ receptor. Cell 95: 779-791.

Viera, A.V., Lamaze, C., and Schimdt, S.L. 1996. Control of EGF receptor signaling by clathrin-mediated endocytosis. Science 274: 2086-2089.

Vert, G., Nemhauseer, J.L., Geldner, N., Hong, F., and Chory, J. 2005. Molecular mechanisms of steroid hormone signaling in plants. Annu. Rev. Cell Dev. Biol. 21: 177-201.

Zazimalova, E., Krecek, P., Skuda, P., Hoyerova, K., and Petrasek, J. 2007. Polar transport of the plant hormone auxinThe role of PIN-FORMED (PIN) proteins. Cell. Mol. Life Sci. doi: 10.1007/s00018-007-6566-4. 


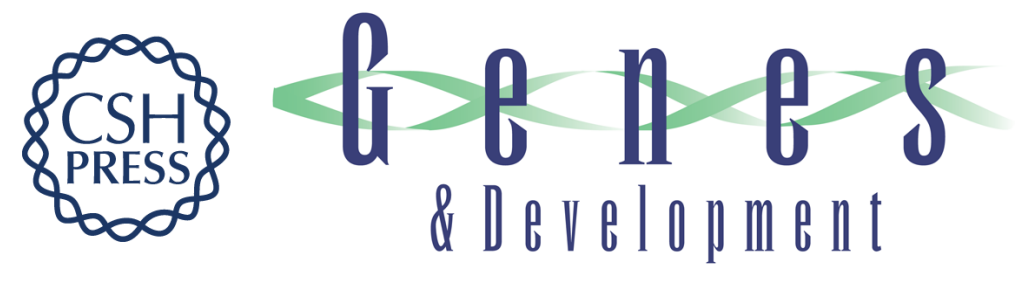

\section{Signaling from plant endosomes: compartments with something to say!}

Natasha Raikhel and Glenn Hicks

Genes Dev. 2007, 21:

Access the most recent version at doi:10.1101/gad.1577607
Related Content Endosomal signaling of plant steroid receptor kinase BRI1
Niko Geldner, Derek L. Hyman, Xuelu Wang, et al.
Genes Dev. July , 2007 21: 1598-1602
References This article cites 21 articles, 11 of which can be accessed free at:
http://genesdev.cshlp.org/content/21/13/1578.full.html\#ref-list-1
Articles cited in:
http://genesdev.cshlp.org/content/21/13/1578.full.html\#related-urls
License
Email Alerting
Service $\begin{aligned} & \text { Receive free email alerts when new articles cite this article - sign up in the box at the top } \\ & \text { right corner of the article or click here. }\end{aligned}$

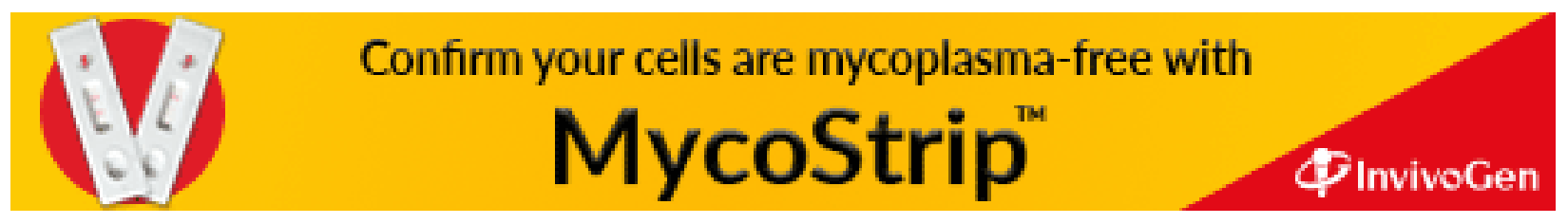

